\title{
Monolithically-Integrated Single-Photon Avalanche Diode in a Zero-Change Standard CMOS Process for Low-Cost and Low-Voltage LiDAR Application
}

\author{
Jinsoo Rhim ${ }^{1, * \mathbb{D}}$, Xiaoge Zeng ${ }^{1}$, Zhihong Huang ${ }^{1}$, Sai Rahul Chalamalasetti ${ }^{1}$, \\ Marco Fiorentino ${ }^{1}$, Raymond Beausoleil ${ }^{1}$ and Myung-Jae Lee ${ }^{2}$ \\ 1 Hewlett Packard Labs, Hewlett Packard Enterprise, Palo Alto, CA 94304, USA; \\ xiaoge.zeng.temp@hpe.com (X.Z.); zhihong.huang.temp@hpe.com (Z.H.); \\ sai.rahul.chalamalasetti.temp@hpe.com (S.R.C.); marco.fiorentino.temp@hpe.com (M.F.); \\ ray.beausoleil.temp@hpe.com (R.B.) \\ 2 Center for Optoelectronic Materials and Devices, Korea Institue of Science and Technology (KIST), \\ Seoul 02792, Korea; fodlmj@gmail.com \\ * Correspondence: peter.jin.rhim@hpe.com
}

Received: 30 April 2019; Accepted: 21 June 2019; Published: 25 June 2019

\begin{abstract}
We present a single-photon sensor based on the single-photon avalanche diode (SPAD) that is suitable for low-cost and low-voltage light detection and ranging (LiDAR) applications. It is implemented in a zero-change standard $0.18-\mu \mathrm{m}$ complementary metal oxide semiconductor process at the minimum cost by excluding any additional processing step for customized doping profiles. The SPAD is based on circular shaped $\mathrm{P}+/ \mathrm{N}$-well junction of $8-\mu \mathrm{m}$ diameter, and it achieves low breakdown voltage below $10 \mathrm{~V}$ so that the operation voltage of the single-photon sensor can be minimized. The quenching and reset circuit is integrated monolithically to capture photon-generated output pulses for measurement. A complete characterization of our single-photon sensor is provided.
\end{abstract}

Keywords: single photon avalanche diode; monolithic integration; zero-change standard CMOS technology

\section{Introduction}

Light detection and ranging (LiDAR) has attracted significant research and development interest over recent years as demands for three-dimensional (3D) imaging technologies have increased in various fields including automotive vehicles, drones, robots, and many other scientific, medical and consumer applications [1,2]. Among others, single-photon avalanche diode (SPAD) technology is a critical building block of such LiDAR systems as it can simultaneously improve sensitivity and timing accuracy [3]. Especially, SPADs implemented in a standard complementary metal oxide semiconductor (CMOS) process is the key that enables high-volume production of low-cost single-photon sensors. Although many efforts have been focusing on realizing CMOS-compatible SPADs and single-photon sensors in deep-submicron CMOS technology [4-16], the majority of them rely on non-standard processes with customized layers that increase the cost and design complexity.

In this article, we present a SPAD-based single-photon sensor that is suitable for low-cost and low-voltage LiDAR systems in mobile devices and automotive vehicles. Our sensor is fully compatible with a standard 0.18- $\mu \mathrm{m}$ CMOS process where our SPAD and active quenching and reset circuit (AQRC) are monolithically integrated at the minimum cost as it excludes any of additional processing step for customized doping profile. Our sensor is carefully designed to minimize the operation voltage without sacrificing a significant amount of performance. We provide a full characterization including 
current-voltage characteristics, dark-count rate (DCR), afterpulsing probability, photon detection probability (PDP), and photon timing jitter.

\section{Single-Photon Sensor}

Figure $1 \mathrm{a}, \mathrm{b}$ shows the microscope image of the SPAD-based single-photon sensor and the cross-sectional view of SPAD, respectively, which is fabricated in standard $180 \mathrm{~nm}$ CMOS technology (1P6M mixed-signal and RF applications) from TSMC. Our SPAD is based on a $\mathrm{P}^{+} / \mathrm{N}$-well junction in a circular shape, and the diameter is $8 \mu \mathrm{m}$. P-well guard-ring that has $2-\mu \mathrm{m}$ width surrounds the junction to protect the device from premature breakdown at the device perimeter, which can be confirmed by a light emission test at $15 \mathrm{~V}$ of reverse bias voltage as shown in Figure 1a. An additional shallow-trench isolation (STI) guard-ring is implemented outside of the P-well guard-ring to prevent lateral tunneling in between $\mathrm{P}^{+}$and $\mathrm{N}^{+}$contact regions. However, such STI may dramatically increase the density of deep-level carrier generation centers at its interface, especially when it is located close to the multiplication region of SPAD [17]. For this reason, the STI is located outside the P-well guard-ring to make sure that only a negligible amount of defect contributes to the noise of SPAD and its size is minimized to have a better fill factor. The deep N-well layer implemented beneath the junction not only connects the contact regions for the cathode but also extends the photon-absorption region into deeper silicon substrate so that more carriers generated from photons at near-infrared (NIR) wavelengths are captured and achieves higher PDP. The sensor occupies $20 \mu \mathrm{m} \times 40 \mu \mathrm{m}$ of area in total and the active area of SPAD is $50.24 \mu^{2}$, which results in $6.3 \%$ of fill-factor for a single pixel. Such a fill factor is expected to improve by the factor of two or more for a linear or two-dimensional array by sharing deep the $\mathrm{N}$-well of the adjacent SPADs and optimizing the circuit design. The fill factor can be further improved by using micro lenses [18].

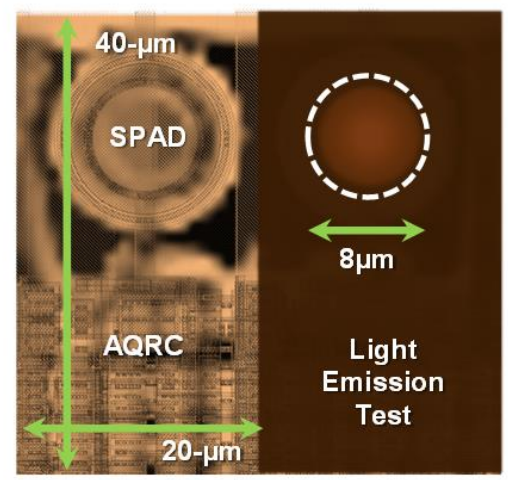

(a)

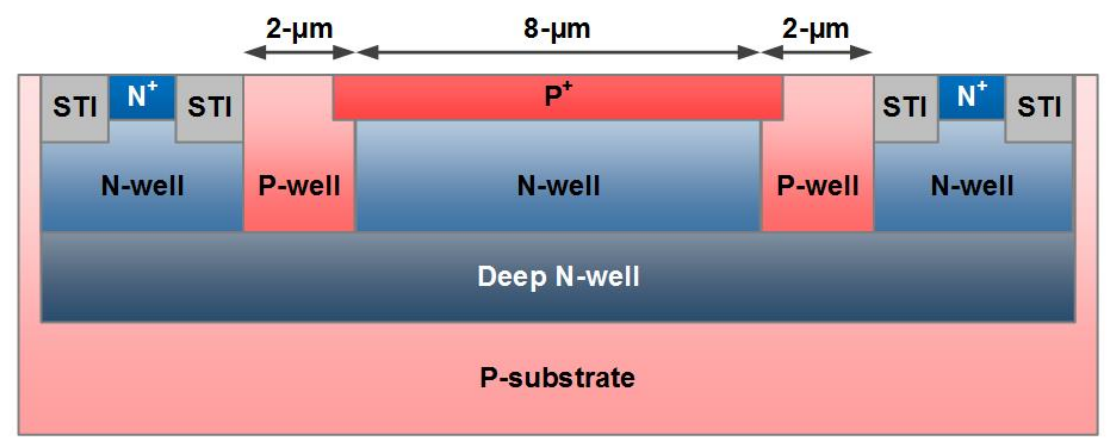

(b)

Figure 1. (a) Microscope image of the fabricated single-photon sensor and the light emission test result; (b) Cross-sectional view of a single-photon avalanche diode (SPAD). 
Figure 2 illustrates the circuit diagram of our AQRC and the output waveform of the SPAD. For Geiger-mode operation, reverse bias voltage beyond its breakdown is applied to the cathode of the SPAD while the anode is connected to the AQRC so that output pulses of the SPAD are properly shaped and then provided to field programmable gate arrays (FPGA) or other equipment for measurement. For an active quenching operation, a p-type transistor and a strong-arm latch-based comparator form a closed loop so that the anode of SPAD is quickly charged to the quenching voltage (VQ) through the PMOS transistor once it gets larger than the threshold voltage (Vth) of the comparator. Such anode voltage then turns on the n-type transistor for an active reset operation after some period of time, which is known as the dead-time of the sensor, and it can vary from 20 to $30 \mathrm{~ns}$ by a programmable delay line. The AQRC is implemented with $3.3 \mathrm{~V} \mathrm{I} / \mathrm{O}$ transistors with a thick gate to withstand large overdrive voltages that comes from the reverse bias voltage of the SPAD for Geiger-mode operation.
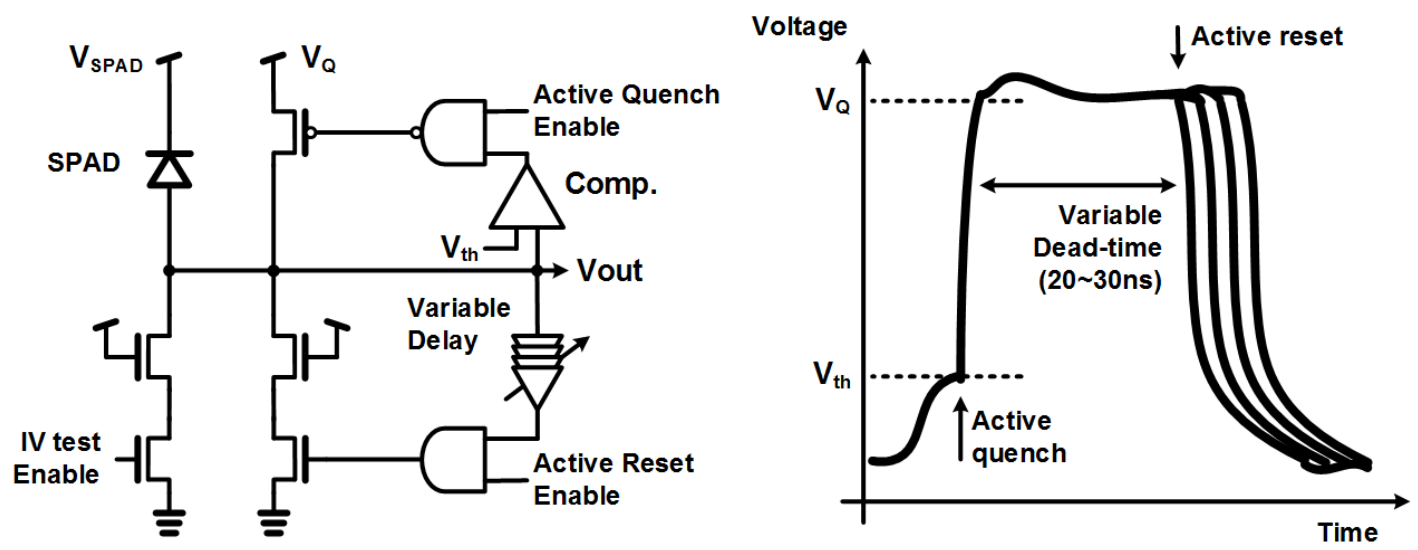

Figure 2. Circuit diagram of an active quenching and reset circuit (AQRC) and the simulated output waveform.

\section{Measurement Results}

Figure 3 shows IV characteristics of our SPAD under the dark condition at different temperatures, and the inset plots the temperature dependency of the breakdown voltage $\left(\mathrm{V}_{\mathrm{BR}}\right)$. The AQRC is disabled when measuring the IV characteristics, and the amount of current flowing through the diode is integrated for a few milliseconds. Our SPAD exhibits a dark current of $100 \mathrm{pA}$ in range before breakdown and the current increases abruptly at the reverse bias voltage of $9.98 \mathrm{~V}$ on average at $300 \mathrm{~K}$, where the variation is less than $10 \mathrm{mV}$ within 32 measured devices. Such low $V_{\mathrm{BR}}$ is achieved due to the higher doping concentration level of N-well than deep N-well for given CMOS technology, and it is critical for minimizing the operation voltage of the target LiDAR systems. $\mathrm{V}_{\mathrm{BR}}$ linearly increases from 9.9 to $10.14 \mathrm{~V}$ as the temperature varies from 290 to $320 \mathrm{~K}$ as inset shows, and the resulting temperature coefficient of $8 \mathrm{mV} / \mathrm{K}$ indicates a weak dependence on the temperature. 


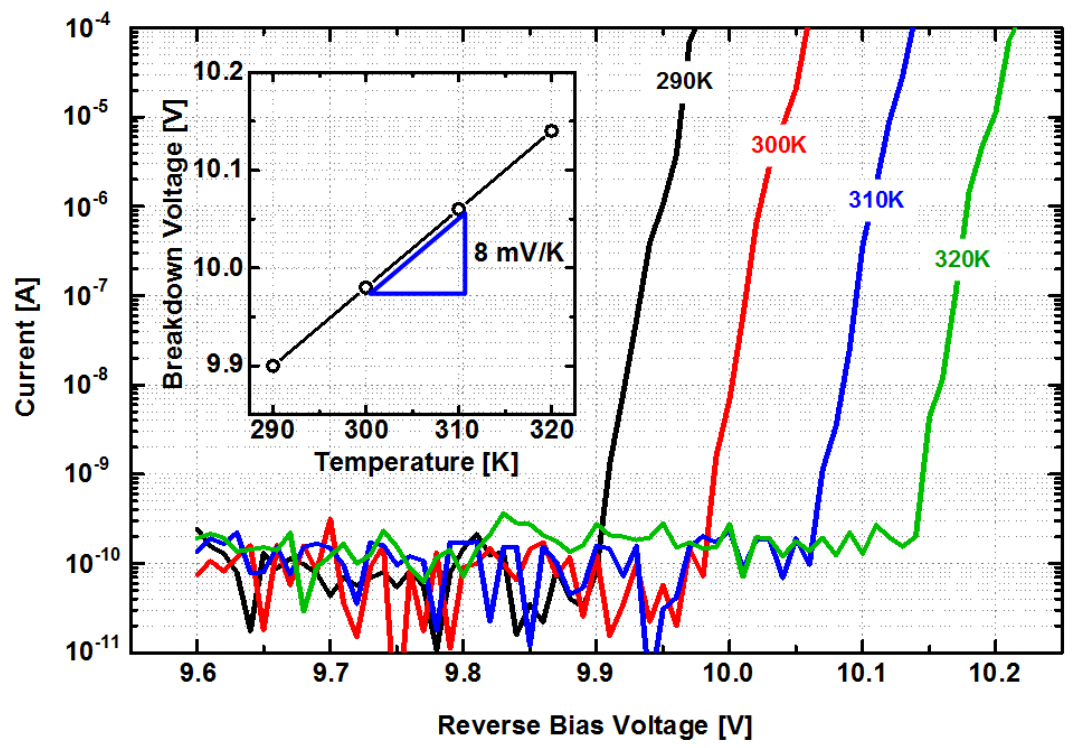

Figure 3. IV characteristics of SPAD. Inset plots temperature dependence of excess bias voltage $\left(\mathrm{V}_{\mathrm{ex}}\right)$.

Figure 4 a shows normalized DCR values as a function of excess bias voltage $\left(V_{\mathrm{ex}}\right)$, which is the difference between applied reverse bias and breakdown voltage, at different temperatures. The normalized DCR increases from 1.3 to $10.3 \mathrm{kcps} / \mu \mathrm{m}^{2}$ at $300 \mathrm{~K}$ as $\mathrm{V}_{\text {ex }}$ changes from 1 to $2 \mathrm{~V}$ and such strong exponential dependence of DCR on $\mathrm{V}_{\mathrm{ex}}$ is an indication that band-to-band tunneling is a dominant contributor of DCR rather than Shockley-Read-Hall recombination or thermal generation. This can be confirmed with low activation energy levels $\left(\mathrm{E}_{\mathrm{a}}\right)$ extracted from the Arrhenius plot shown in Figure $4 \mathrm{~b}$ where the values are $0.114,0.161$, and $0.197 \mathrm{eV}$ for $\mathrm{V}_{\mathrm{ex}}$ of $1,1.5$, and $2 \mathrm{~V}$, respectively, and the corresponding determination coefficients $\left(R^{2}\right)$ are $0.995,0.997$, and 0.999 , respectively. It should be noted that DCR of our SPAD is relatively larger than some of the SPADs implemented in advanced CMOS processes, but it is still in the acceptable range for the target LiDAR systems where the background ambient light is the dominant noise [19]. In addition, such advanced processes not only increase the fabrication cost but also the operation voltage, which is more critical to the target LiDAR systems.

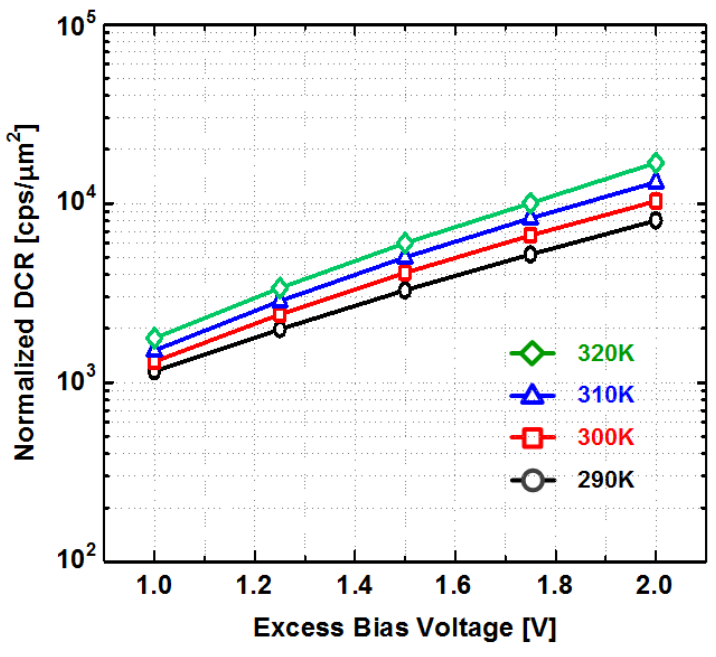

(a)

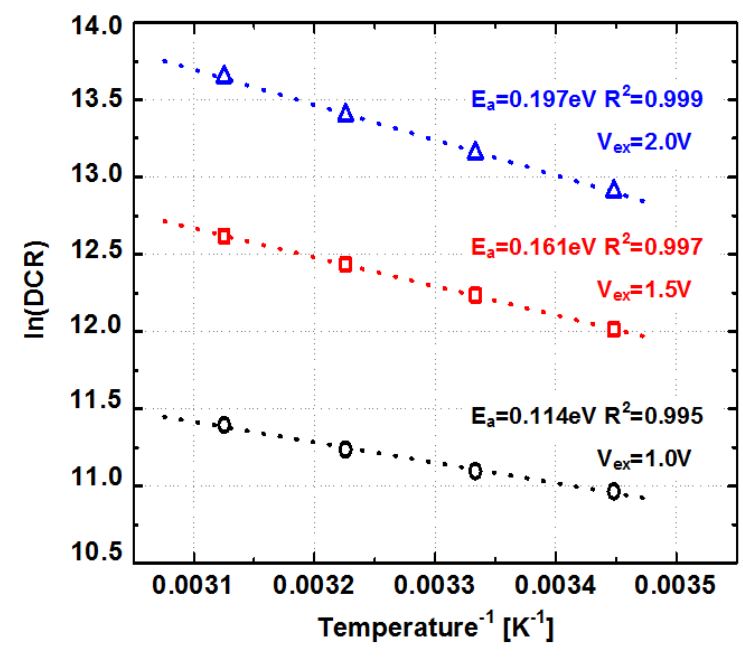

(b)

Figure 4. (a) Normalized dark-count rate (DCR) as a function of $\mathrm{V}_{\mathrm{ex}}$ at different temperatures; (b) Arrhenius plot with extracted activation energy and determination coefficient for the curve fit (dotted line). 
Figure 5 plots the histogram of inter-avalanche times (IATs) under the dark condition with a fitted exponential curve and the inset shows the dependence of afterpulsing probability on the dead-time of the sensor. The histogram of primary dark counts are known to follow an ideal Poisson distribution [20] and, therefore, the afterpulsing probability is statistically derived by taking the fraction of IATs that deviate from an ideal exponential distribution. Our SPAD exhibits afterpulsing probability of $4.3 \%$ with $\mathrm{V}_{\mathrm{ex}}$ of $2 \mathrm{~V}$ when the dead-time is $20 \mathrm{~ns}$, and it can be reduced to less than $1 \%$ by increasing the dead-time to $30 \mathrm{~ns}$.

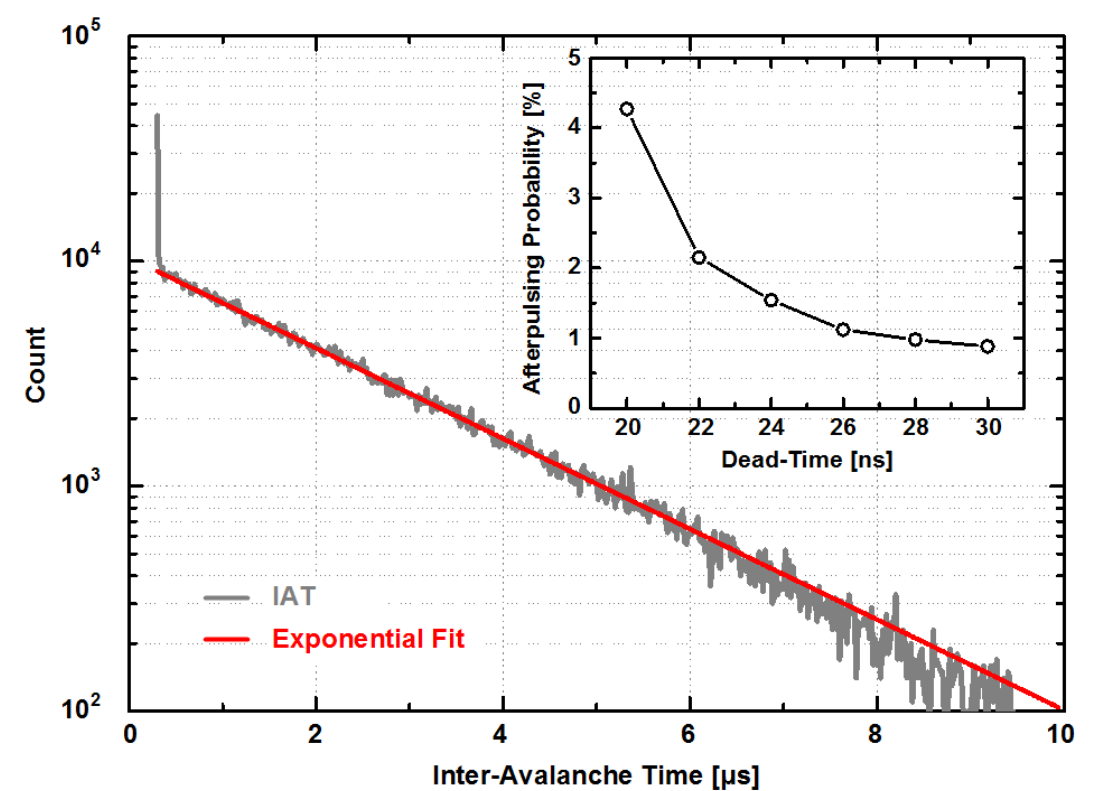

Figure 5. Histogram of inter-avalanche times (IAT) with exponential fit. Inset shows the dead-time dependency of afterpulsing probability.

Figure 6 shows the PDP of the SPAD as a function of wavelength at different $\mathrm{V}_{\text {ex }}$. For this measurement, a Xenon light source with a monochromator (DMC1-04 from Optometrics) is used to select the wavelength of the light and radiate it into an integrating sphere (IS200 from Thorlabs) and the reference photodiode (S130C from Thorlabs) is used to calculate PDP. The maximum PDP of our SPAD is $30.4 \%$ at the wavelength of $535 \mathrm{~nm}$ and $\mathrm{V}_{\mathrm{ex}}$ of $2 \mathrm{~V}$. Although PDP decreases with wavelengths as photon penetration depth starts to exceed the depth of $\mathrm{P}^{+} / \mathrm{N}$-well junction, our SPAD still achieves as high a PDP as 5.6\% and 3.8\% at 850 and $905 \mathrm{~nm}$, respectively. This is mainly due to the deep N-well implemented beneath the junction that extends the photon-absorption region into deeper substrate where more photons of longer wavelengths are absorbed and contribute to avalanche multiplication process. Our SPAD achieves better or comparable PDP than others fabricated in non-standard processes in similar technology nodes. Such NIR-enhanced PDP characteristics are critical for LiDAR applications as many of them operate at 850 or $905 \mathrm{~nm}$ because of silicon compatibility, minimum absorption at free-space by water, and eye-safety issues [21]. 


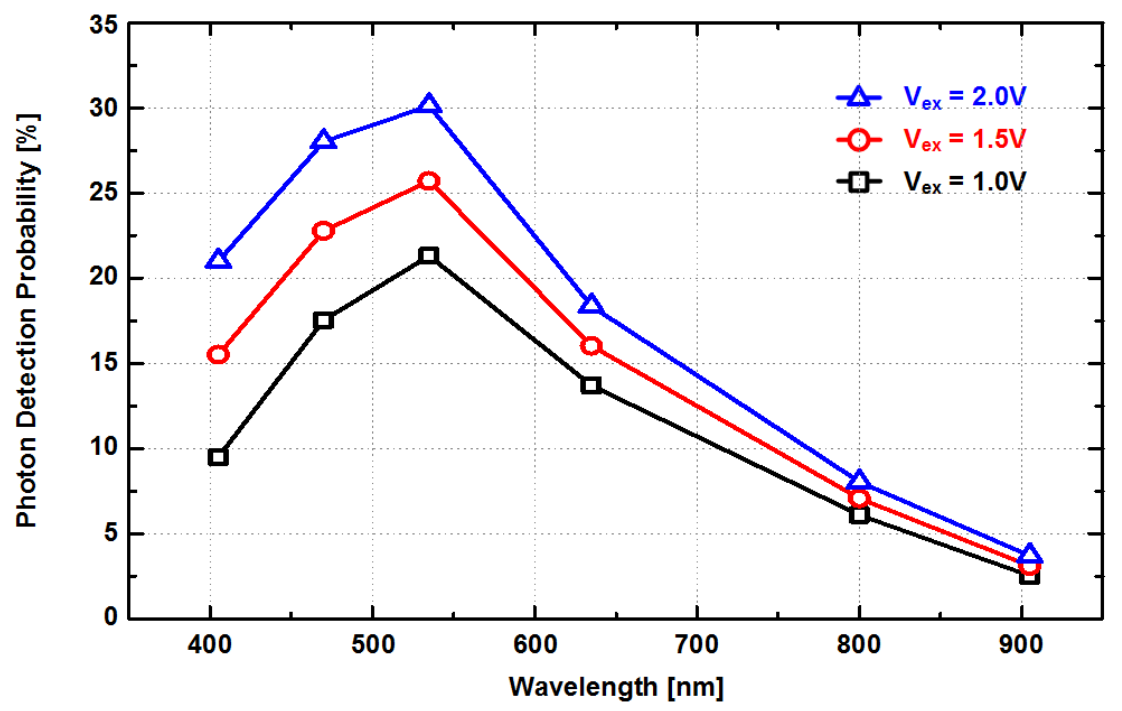

Figure 6. Photon detection probability (PDP) values as a function of wavelength at different $\mathrm{V}_{\mathrm{ex}}$.

Figure 7 shows a normalized histogram of time response based on time-correlated single-photon counting (TCSPC) technique, and the inset plots timing jitter, full-width at half-maximum (FWHM), as a function of $\mathrm{V}_{\mathrm{ex}}$. For this measurement, a LiDAR demonstration board (EPC9126 from EPC) that consists of ground-referenced enhanced GaN field effect transistor driven by a gate driver (LMG1020 from Texas Instruments) and $905 \mathrm{~nm}$ pulsed laser diode (DPGEW1S09H from Excelitas) were used. The measured timing jitter is $110 \mathrm{ps}$ at $\mathrm{V}_{\mathrm{ex}}$ of $1 \mathrm{~V}$, and it can be further improved to 92 ps with $\mathrm{V}_{\mathrm{ex}}$ of $2 \mathrm{~V}$ including the contribution from the laser diode, which corresponds to a depth resolution of $3 \mathrm{~cm}$ for the time-of-flight measurement, and such small jitter is mainly due to the sharp transition of the monolithically-integrated AQRC.

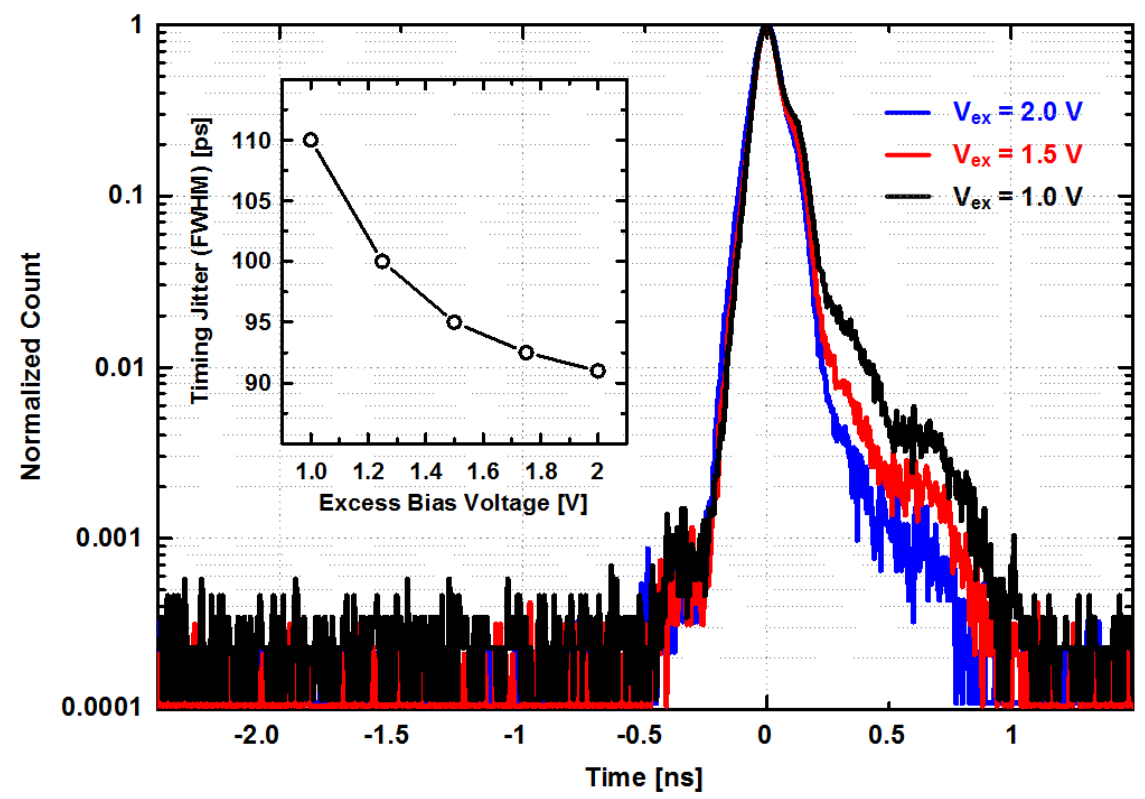

Figure 7. Time response of SPAD. Inset shows the dependency of $\mathrm{V}_{\mathrm{ex}}$ on the timing jitter (full-width at half-maximum (FWHM)).

The performance of our SPAD is summarized in Table 1 and compared with other SPADs implemented in standard CMOS technologies. Although our SPAD has higher DCR, it achieves the lowest $\mathrm{V}_{\mathrm{BR}}$ and the shortest dead-time while exhibiting better or comparable PDP, afterpulsing probability, and timing jitter at the target wavelength of $905 \mathrm{~nm}$. 
Table 1. Performance summary and comparison.

\begin{tabular}{|c|c|c|c|c|c|c|c|}
\hline & This Work & [13] & [14] & [15] & [16] & [10] & [11] \\
\hline Technology & $0.18-\mu \mathrm{m}$ & $0.15-\mu \mathrm{m}$ & $0.18-\mu \mathrm{m}$ & $0.15-\mu \mathrm{m}$ & $0.13-\mu \mathrm{m}$ & $0.18-\mu \mathrm{m}$ & $0.13-\mu \mathrm{m}$ \\
\hline Process & Standard CMOS & Standard CMOS & Standard CMOS & Standard CMOS & Standard CMOS & $\begin{array}{l}\text { High-Voltage } \\
\text { CMOS }\end{array}$ & $\begin{array}{l}\text { CMOS Image } \\
\text { Sensor }\end{array}$ \\
\hline $\begin{array}{l}\text { Junction } \\
\text { Structure }\end{array}$ & $\begin{array}{c}\mathrm{P}^{+} / \\
\mathrm{N}-\text { well }\end{array}$ & $\begin{array}{c}\mathrm{P}^{+} / \\
\mathrm{N} \text {-well }\end{array}$ & $\begin{array}{c}\mathrm{P}^{+} / \\
\mathrm{N} \text {-well }\end{array}$ & $\begin{array}{c}\mathrm{P}^{+} / \\
\mathrm{N}-\text { well }\end{array}$ & $\begin{array}{c}\mathrm{N}+/ \\
\text { P-well }\end{array}$ & $\begin{array}{l}\text { Deep P-well/ } \\
\text { Buried-N }\end{array}$ & $\begin{array}{c}\text { Deep N-well/ } \\
\text { P-sub }\end{array}$ \\
\hline $\begin{array}{l}\text { Guard-Ring } \\
\text { Structure }\end{array}$ & P-well & $\begin{array}{l}\text { Deep } \\
\text { N-well }\end{array}$ & P-well & P epi & N-well & P-well & $\begin{array}{c}\text { P-epi } \\
\text { Virtual }\end{array}$ \\
\hline Shape & Circle & Square & Octagon & Circle & Square & Circular & Circular \\
\hline $\mathrm{V}_{\mathrm{BR}}$ & $9.98 \mathrm{~V}$ & $18.01 \mathrm{~V}$ & $10.2 \mathrm{~V}$ & $16.1 \mathrm{~V}$ & $11.3 \mathrm{~V}$ & $49.9 \mathrm{~V}$ & $20 \mathrm{~V}$ \\
\hline $\mathrm{V}_{\mathrm{ex}}$ & $2 \mathrm{~V}$ & $3 \mathrm{~V}$ & $2 \mathrm{~V}$ & $3.5 \mathrm{~V}$ & $2.2 \mathrm{~V}$ & $5 \mathrm{~V}$ & $2 \mathrm{~V}$ \\
\hline $\begin{array}{c}\text { Normalized } \\
\text { DCR }\end{array}$ & $10300 \mathrm{cps} / \mu \mathrm{m}^{2}$ & $0.4 \mathrm{cps} / \mu \mathrm{m}^{2}$ & $\begin{array}{c}7780 \mathrm{cps} / \mu \mathrm{m}^{2} \\
@ 0.5 \mathrm{~V}_{\mathrm{ex}}\end{array}$ & $1.53 \mathrm{cps} / \mu \mathrm{m}^{2}$ & $1000 \mathrm{cps} / \mu \mathrm{m}^{2}$ & $0.68 \mathrm{cps} / \mu \mathrm{m}^{2}$ & $1.125 \mathrm{cps} / \mu \mathrm{m}^{2}$ \\
\hline $\begin{array}{l}\text { Afterpulsing } \\
\text { Probability } \\
\text { (Dead Time) }\end{array}$ & $\begin{array}{c}1 \% \\
(30 \mathrm{~ns})\end{array}$ & $\begin{array}{c}0.85 \% \\
(150 \mathrm{~ns})\end{array}$ & N/A & $\begin{array}{c}0.45 \% \\
(100 \mathrm{~ns})\end{array}$ & N/A & $\begin{array}{c}1.6 \% \\
(20 \mathrm{~ns})\end{array}$ & $\begin{array}{c}4 \% \\
@ 12 \mathrm{~V}_{\mathrm{ex}} \\
(\mathrm{N} / \mathrm{A})\end{array}$ \\
\hline $\begin{array}{l}\text { PDP Peak } \\
(\lambda)\end{array}$ & $\begin{array}{c}30.4 \% \\
(530 \mathrm{~nm})\end{array}$ & $\begin{array}{c}27.5 \% \\
(450 \mathrm{~nm})\end{array}$ & $\begin{array}{c}5.5 \% \\
(450 \mathrm{~nm})\end{array}$ & $\begin{array}{c}25 \% \\
(470 \mathrm{~nm})\end{array}$ & $\begin{array}{c}13 \% \\
(570 \mathrm{~nm})\end{array}$ & $\begin{array}{c}22 \% \\
(570 \mathrm{~nm})\end{array}$ & $\begin{array}{c}72 \% \\
@ 12 \mathrm{~V}_{\mathrm{ex}} \\
(550 \mathrm{~nm})\end{array}$ \\
\hline $\begin{array}{c}\text { PDP } \\
\text { @ } 905 \mathrm{~nm}\end{array}$ & $3.8 \%$ & $2 \%$ & N/A & N/A & N/A & $2.8 \%$ & $5 \%$ \\
\hline $\begin{array}{c}\text { FWHM } \\
\text { Timing Jitter } \\
(\lambda)\end{array}$ & $\begin{array}{c}92 \mathrm{ps} \\
(905 \mathrm{~nm})\end{array}$ & $\begin{array}{c}42 \mathrm{ps} \\
@ 4 \mathrm{~V}_{\mathrm{ex}} \\
(831 \mathrm{~nm})\end{array}$ & N/A & $\begin{array}{c}92 \mathrm{ps} \\
(470 \mathrm{~nm})\end{array}$ & N/A & $\begin{array}{c}200 \mathrm{ps} \\
(720 \mathrm{~nm})\end{array}$ & N/A \\
\hline
\end{tabular}




\section{Conclusions}

In conclusion, a monolithically-integrated single-photon sensor fabricated in a zero-change standard $0.18-\mu \mathrm{m}$ CMOS process is presented and characterized. It should be emphasized that our SPAD uses none of the additional processing steps to minimize the cost and is carefully designed to minimize the operation voltage without significant performance degradation. We expect our sensor to play a critical role in realizing single-photon sensors for low-cost and low-voltage LiDAR applications.

Author Contributions: Conceptualization, J.R. and M.-J.L.; methodology, J.R.; software, X.Z., Z.H. and S.R.C.; validation, J.R. and M.-J.L.; writing—original draft preparation, J.R.; writing—review and editing, J.R. and M.-J.L.; supervision, M.F. and R.B.

Funding: This research received no external funding.

Conflicts of Interest: The authors declare no conflict of interest.

\section{References}

1. Hadfield, R.H. Single-photon detectors for optical quantum information applications. Nat. Photon. 2009, 3, 696-705. [CrossRef]

2. Bruschini, C.; Homulle, H.; Charbon, E. Ten years of biophotonics single-photon SPAD imager applications retrospective and outlook. In Proceedings of the Advanced Photon Counting Techniques XI, Anaheim, CA, USA, 9-13 April 2017.

3. Ghioni, M.; Gulinatti, A.; Rech, I.; Zappa, F.; Cova, S. Progress in silicon single-photon avalanche diodes. IEEE J. Sel. Topics Quantum Electron. 2007, 13, 852-862. [CrossRef]

4. Lee, M.-J.; Sun, P.; Charbon, E. A first single-photon avalanche diode fabricated in standard SOI CMOS technology with a full characterization of the device. Opt. Express 2015, 23, 13200-13209. [CrossRef] [PubMed]

5. Pellegrini, S.; Rae, B. Fully industrialised single photon avalanche diodes. In Proceedings of the Advanced Photon Counting Techniques XI, Anaheim, CA, USA, 9-13 April 2017.

6. Pellegrini, S.; Rae, B.; Pingault, A.; Golanski, D.; Jouan, S.; Lapeyre, C.; Mamdy, B. Industrialised SPAD in $40 \mathrm{~nm}$ Technology. In Proceedings of the 2017 IEEE International Electron Devices Meeting (IEDM), San Francisco, CA, USA, 2-6 December 2017.

7. Niclass, C.; Soga, M.; Matsubara, H.; Kato, S.; Kagami, M. A 100-m range 10-frame/s 340x96-pixel time-of-flight depth sensor in 0.18- $\mu \mathrm{m}$ CMOS. IEEE J. Solid-State Circuits 2013, 48, 559-572. [CrossRef]

8. Niclass, C.; Gersbach, M.; Henderson, R.; Grant, L.; Charbon, E. A single photon avalanche diode implemented in 130-nm CMOS technology. IEEE J. Solid-State Circuits 2007, 13, 863-869. [CrossRef]

9. Karami, M.A.; Gersbach, M.; Yoon, H.-J.; Charbon, E. A new single-photon avalanche diode in 90nm standard CMOS technology. Opt. Express 2010, 18, 22158-22166. [CrossRef] [PubMed]

10. Huang, L.D.; Wu, J.Y.; Wang, J.P.; Tsai, C.M.; Huang, Y.H.; Wu, D.R.; Lin, S.D. Single-photon avalanche diodes in 0.18- $\mu \mathrm{m}$ high-voltage CMOS technology. Opt. Express 2017, 25, 13333-13339. [CrossRef] [PubMed]

11. Webster, E.A.G.; Grant, L.A.; Henderson, R.K. A high- performance single-photon avalanche diode in 130-nm CMOS imaging technology. IEEE Electron Device Lett. 2012, 33, 1589-1591. [CrossRef]

12. Veerappan, C.; Charbon, E. CMOS SPAD based on photo-carrier diffusion achieving PDP $>40 \%$ from 440 to $580 \mathrm{~nm}$ at $4 \mathrm{~V}$ excess bias. IEEE Photon. Technol. Lett. 2015, 27, 2445-2448. [CrossRef]

13. Xu, H.; Pancheri, L.; Betta, G.-F.D.; Stoppa, D. Design and characterization of a $\mathrm{p}+/ \mathrm{n}$-well SPAD array in 150nm CMOS process. Opt. Express 2017, 25, 12765-12778. [CrossRef] [PubMed]

14. Faramarzpour, N.; Deen, M.J.; Shirani, S.; Fang, Q. Fully integrated single photon avalanche diode detector in standard CMOS 0.18- $\mu \mathrm{m}$ technology. IEEE Tran. Electron Devices 2008, 55, 760-767. [CrossRef]

15. Pancheri, L.; Stoppa, D. Low-noise single photon avalanche diodes in $0.15 \mu \mathrm{m}$ CMOS technology. In Proceedings of the 2011 European Solid-State Device Research Conference (ESSDERC), Helsinki, Finland, 12-16 September 2011. [CrossRef]

16. Palubiak, D.P.; El-Desouki, M.M.; Marinov, O.; Deen, M.J.; Fang, Q. High-speed, single photon avalanche photodiode imager for biomedical applications. IEEE Sens. J. 2011, 11, 2401-2412. [CrossRef]

17. Finkelstein, H.; Hsu, M.J.; Esener, S. STI-bounded single-photon avalanche diode in a deep-submicrometer CMOS technology. IEEE Electron Device Lett. 2006, 27, 887-889. [CrossRef] 
18. Pavia, J.M.; Wolf, M.; Charbon, E. Measurement and modeling of microlenses fabricated on single-photon avalanche diode arrays for fill factor recovery. Opt. Express 2014, 22, 4202-4213. [CrossRef] [PubMed]

19. Katz, A.; Eshkoli, A.; Feningstein, A.; Jackson, C.; Nemirovsky, Y. Design considerations of CMOS Si photomultiplier for long range LIDAR. In Proceedings of the 2017 IEEE International Conference on Microwaves, Antennas, Communications and Electronic Systems (COMCAS), Tel Aviv, Israel, 13-15 November 2017.

20. Palubiak, D.P.; Li, Z.; Deen, M.J. Afterpulsing characteristics of free-running and time-gated SPADs in 130nm CMOS. IEEE Tran. Electron Devices 2015, 62, 3727-3733. [CrossRef]

21. Williams, G.M. Optimization of eyesafe avalanche photodiode lidar for automobile safety and autonomous navigation systems. Optical Eng. 2017, 56. [CrossRef]

(C) 2019 by the authors. Licensee MDPI, Basel, Switzerland. This article is an open access article distributed under the terms and conditions of the Creative Commons Attribution (CC BY) license (http://creativecommons.org/licenses/by/4.0/). 